\title{
GCU
}

Glasgow Caledonian

University

University for the Common Good

\section{Eliciting public values on health inequalities: missing evidence for policy windows?}

McHugh, Neil

Published in:

Evidence and Policy

DOI:

$10.1332 / 174426421 \times 16286783870175$

Publication date:

2022

Document Version

Author accepted manuscript

Link to publication in ResearchOnline

Citation for published version (Harvard):

McHugh, N 2022, 'Eliciting public values on health inequalities: missing evidence for policy windows?', Evidence and Policy, vol. 18, no. 4, pp. 733-745. https://doi.org/10.1332/174426421X16286783870175

\section{General rights}

Copyright and moral rights for the publications made accessible in the public portal are retained by the authors and/or other copyright owners and it is a condition of accessing publications that users recognise and abide by the legal requirements associated with these rights.

Take down policy

If you believe that this document breaches copyright please view our takedown policy at https://edshare.gcu.ac.uk/id/eprint/5179 for details of how to contact us. 
Title: Eliciting public values on health inequalities: missing evidence for policy windows?

Author Name: Neil McHugh

Affiliation: Glasgow Caledonian University, United Kingdom

\begin{abstract}
Background: There is a widening health divide in the UK despite health inequalities being a long-standing subject of policy and research. New types of evidence are needed.
\end{abstract}

Key points for discussion: Knowledge of public values for non-health policies and their associated (non-)health outcomes is currently missing from decision-making processes. Eliciting public values using stated preference techniques can provide insights on what the general public would be willing to give-up for different distributions of (non-)health outcomes and the policies that can achieve them. To understand the role this evidence could have in decision-making processes, Kingdon's multiple streams analysis (MSA) is used as a policy lens to explore how evidence of public values could affect policy processes for ways to tackle health inequalities.

Conclusions and implications: This paper outlines how evidence of public values could be elicited through the use of stated preference techniques and suggests this could facilitate the creation of policy windows for tackling health inequalities. Additionally, Kingdon's MSA helps make explicit six cross-cutting issues when generating this new form of evidence. This suggests the need to explore reasons for public values and how decision-makers would use such 
evidence. With an awareness of these issues, evidence on public values has the potential to support upstream policies to tackle health inequalities.

Keywords: public values; health inequalities; policy windows

Word count: 5,192 words

\section{Key Messages:}

- UK health inequalities are widening despite being a long-standing subject of policy and research

- We are missing evidence of public values for non-health policies and their (non-)health outcomes

- Kingdon's MSA is used to consider the role this evidence could have in decisionmaking processes

- This evidence could facilitate the creation of policy windows for tackling health inequalities 


\section{Background}

In the UK, there is a health divide. Individuals who are worse-off in terms of socioeconomic position have shorter lives in poorer health than those who are better-off (Marmot, 2010). Worryingly, despite the long-standing attention of researchers and policy makers health gaps have widened in recent years (Marmot et al., 2020a; Scottish Government, 2020; Smith et al., 2015) and have been exacerbated by the COVID-19 pandemic (Bambra et al., 2020; Marmot et al., 2020b). Health policies alone cannot redress this situation because health is determined by social, economic and environmental factors (Dahlgren and Whitehead, 2007; WHO, 2008). Rather than focusing downstream on modifying individuals' health behaviours, action is required on upstream underlying causes of poor health (Douglas, 2016; Marmot, 2010). This requires that health outcomes are considered by non-health sectors such as social security, housing and education and has led to calls for healthy public policy or health in all policies (Solar et al., 2009; WHO, 2014, 2012). However, such an approach is challenging as it necessitates intersectoral approaches to policy making and because acting on structural determinants of health is more likely to require policy windows through which to implement specific policy solutions for tackling health inequalities (Cairney and St Denny, 2020; Kingdon, 2011). In this paper, it is argued that one type of evidence, currently missing from decision-making processes is knowledge of public values for non-health policies and their associated (non-)health outcomes. Such evidence could potentially facilitate the creation of policy windows for tackling health inequalities.

The paper is in two sections. The first section introduces public values and outlines reasons for eliciting them for tackling health inequalities. The second section uses Kingdon's multiple 
streams analysis (MSA) as a policy lens to explore how evidence of public values could affect policy processes for ways to tackle health inequalities.

\section{Public Values}

\section{What are public values?}

The term public values requires some unpacking. First, there is no one public. Many different public(s) can be assembled with people asked to occupy different roles depending on the situation (Baker et al., 2021; Barnett, 2008; Escobar, 2017; Stewart, 2016). Different subsets, or communities, of people can be constructed who share a common characteristic around, for example, place and/or interest (Brunton, 2017; Popay, 2006). People could also be asked to adopt different perspectives, for example, individual, self-interested; societal, other-focused; or, socially inclusive, personal and other-focused (Dolan et al., 2003; Tsuchiya and Watson, 2017). As public values for health inequalities could be elicited in relation to a variety of possible research questions this paper does not provide a prescriptive definition of public(s). However, one clarification is the focus is not on patients or health service users, two commonly used subsets of the public (Fredriksson and Tritter, 2017), as the area of interest includes but extends beyond the health sector.

Value(s) can also take different forms. Baker et al. (2021) differentiate between two forms of value: ethical/philosophical values and economic values. For the former, values are high-level principles or moral standards, such as equity, efficiency, human dignity or security that can be used to justify a choice or decision. For example, different equity principles may be invoked to justify different approaches to allocating a fixed health budget: maximising health outcomes 
(utilitarianism) or equalising health outcomes for all (egalitarianism). It is common to use qualitative methods to elicit these values. For the latter, value is commonly expressed through sacrifice: what is the most you would be willing to give-up in order to achieve a particular change in the world. The maximum trade-off represents the value placed on that change and provides a measurable indication of strength of preference. Values are typically elicited through stated preference techniques that incorporate trade-offs. These techniques are used when we wish to know the value placed on non-market goods, services or programmes. While both types of values are important, particularly in regard to resource allocation decisions, this paper focuses on economic values.

Different types of public values can be elicited. The focus of this paper is on public values for non-health policies and their associated (non-)health outcomes as this evidence is currently missing from decision-making processes. Eliciting these public values using stated preference techniques requires knowledge of a policy’s impact. It is well established that generating such evidence for upstream socio-economic policies that impact on health inequalities is more difficult than for policies further downstream (the 'inverse evidence law') (Bambra et al., 2010; Ogilvie, 2005; Petticrew, 2004). However, recent innovative modelling work has provided a better sense of the potential impact of upstream policies, such as regulatory or tax options, on non-health, population health and health inequality outcomes (see the Scottish Public Health Observatory’s 'Triple I’ Project (McAuley et al., 2016; Richardson et al., 2020). These new insights, in combination with suggestive evidence from systematic literature reviews (for example, Bambra et al. (2010); Thomson et al. (2018); Hillier-Brown et al. (2019)) and expert discussion, can enable the elicitation of public values for non-health policies and their associated (non-)health outcomes. For example, stated preference studies could focus on valuing: policies that impact on (non-)health outcomes across different determinants of health 
(i.e. income, education or environment); policies within one determinant only (i.e. income); and/or policies that are considered upstream only or that range from upstream to those further downstream. Additionally, public values could be explored in relation to how different configurations of the same policy, for example, universal basic income (Richardson et al., 2020), impacts on (non-)health outcomes.

\section{How to elicit public values?}

Public values can be elicited in different ways using different stated preference techniques. The purpose of this paper is not to provide an in-depth discussion of how to elicit public values (for this see, for example, Ryan et al. (2001) and Bateman et al. (2002)). However, brief consideration of two different techniques - Contingent Valuation (CV) and Discrete Choice Experiments (DCEs) - and the different perspectives from which public values can be elicited illustrates important considerations.

CV questions ask respondents to indicate the value they ascribe to a particular good by stating the maximum they would be willing to pay for it. Grounded in welfare economics, CV studies are commonly used to inform regulatory and investment decisions in non-health divisions of government as well as in health (economics) research when no market values exist (HM Treasury, 2020; Ryan et al., 2001). CV questions could ask participants how much they are willing to pay via extra taxation for a range of non-health policies across different determinants of health with (non-)health outcomes. In DCEs respondents evaluate discrete alternatives described by attributes of policies; for example, policy type, non-health outcome impact, population health impact, health inequalities impact and cost. These attributes vary according to a plausible set of levels, for example, for the attribute 'health inequalities impact', levels 
could relate to reductions, increases and no change in health inequalities. Each technique has specific strengths. For example, as DCEs focus on the valuation of attributes they have greater analytic flexibility, in terms of more easily being able to delineate the relative importance of specific attributes (of policies) as well as providing a relative overall value of discrete scenarios. While CV questions more readily mimic the types of decision made in real-life policy making as the focus is on valuing the policy as a whole.

Public values can also be elicited from different perspectives. This is important as members of society may express different values depending on whether they are acting as individuals (personal/self-interested) or as citizens (societal/other-focused) (Dolan et al., 2003; Tsuchiya and Watson, 2017). The former perspective is concerned with individual benefits and the latter with societal benefits. As public values convey different information depending on the perspective participants are asked to adopt the choice of perspective has to relate to the research question under consideration.

\section{Why should public values be elicited for tackling health inequalities?}

There are two broad categories of reasons for eliciting public values for policies that impact on health inequalities - intrinsic and instrumental rationales. Intrinsic rationales relate to democratic arguments for accounting for public values in the allocation of public resources: taxes fund public policies and the general public are affected, positively and negatively, by resource allocation decisions (Baker et al., 2021; Tenbensel, 2010). This assumes that how resources are currently allocated should be indicative of the public value placed on different prospects, and the importance of different kinds of benefits to different beneficiaries. More 
instrumentally, the elicitation of public values can generate new forms of evidence to inform resource allocation decisions.

No studies have elicited public values for non-health policies and their associated (non-)health outcomes. Stated preference research exists on the public's aversion to inequalities in health between socioeconomic groups (McNamara et al., 2020) and there are valuation studies of public health interventions such as water fluoridation and salt reduction (Kristiansen et al., 2006; Shackley and Dixon, 2000). There is also a large stated preference literature on nonhealth policies with non-health outcomes, for example, in environmental and transport sectors (Bahamonde-Birke et al., 2015; Carson and Hanemann, 2005) and there are public attitude/opinion surveys on redistributive non-health policies (for example, Reid et al. (2019)). However, crucially, this research does not ask the public to make trade-offs between different non-health policies where the (non-)health outcomes are made explicit nor to express what, if anything, they would be willing to give-up for different distributions of (non-)health outcomes and the policies that can achieve them. Such an approach can enable the elicitation of the relative importance of different types of non-health policies and/or the outcomes of these policies and the examination of whether public values change depending on how the effects of policies are framed.

While it is now possible to generate this new type of evidence and there are different rationales for doing so it is also important to consider the role this evidence could have in decision-making processes. The next section uses Kingdon's multiple streams analysis (MSA) as a policy lens to explore how evidence of public values could affect policy processes for ways to tackle health inequalities. 


\section{Multiple Streams Analysis (MSA) and health inequalities in the UK}

Within health research there has been a tendency to subscribe to the rational, linear model of policy making - a problem is identified, research responds by producing a solution, this is adopted by politicians and the corresponding policy change is made. However this view of policy making is widely discredited (Exworthy, 2008; Smith, 2013). In reality policy change is a much more complex process. While there are different theories of policy making (Smith and Katikireddi, 2013), one of the most widely applied policy theories (Jones et al., 2016), which explains how and why issues get on the policy agenda is Kingdon's (2011) MSA.

In its original application, MSA details how policy change occurs only when there is a coupling of multiple streams - Problem, Policy and Politics - to create a policy window. Problems are issues which are deemed by decision makers to require attention. The Policy stream is concerned with finding some agreement on which solutions to implement. Politics relates to the receptivity of elected decision makers to particular solutions. Skilled and knowledgeable individuals, called policy entrepreneurs, work to aid the coupling of these streams and to exploit policy windows (for a more complete summary of MSA and the subcomponents underpinning the three streams see, for example, Cairney (2012), Jones et al. (2016) and Zahariadis (2007)).

This model has been applied in a variety of ways to examine health inequalities in the UK. For example, it was used to help explain the contrasting journeys of ideas from research into policy (Smith, 2007), to explore tensions between local and national policymaking (Blackman et al., 2012; Exworthy et al., 2002; Exworthy and Powell, 2004) and to understand the progress of national policy towards tackling health inequalities (Cairney and St Denny, 2020; Exworthy et 
al., 2003). The last application is particularly important for the work proposed here as it highlights the difference between a single policy window and multiple policy windows. As tackling health inequalities requires the adoption of a large number of different and defined policy solutions at different times, multiple policy windows are considered necessary to deliver change (Cairney and St Denny, 2020). Yet despite this range of applications MSA has not been used with, or considered alongside, public values for non-health policies and their associated (non-)health outcomes. The reasons for this are unclear but could relate to different disciplinary perspectives and/or that, as outlined, new evidence on the technical feasibility of upstream ways to impact on (non-)health outcomes has only recently become available. In what follows, how evidence of public values could affect policy processes to facilitate the creation of policy windows for ways to tackle health inequalities is explored followed by discussion of crosscutting issues that must be considered in generating this new form of evidence.

\section{The Problem Stream}

While health inequalities are on the health agenda (Marmot, 2010), non-health sectors may either not recognise health inequalities as a problem or as a problem relevant to their sector. Knowledge of public values for different policy outcomes could aid the recognition of health inequalities as a problem in non-health sectors. The design and implementation of policies always involves choices; different policies exist which can impact on different beneficiaries in different ways. For example, social security and taxation policies can have different impacts on income, population health and health inequalities (Richardson et al., 2020). Public values can provide an indication of the relative importance of different (non-)health outcomes from non-health sector policies. Such insights could potentially help policy entrepreneurs push certain policies up or down the agenda and enable them to pursue different intersectoral policy 
making strategies, such as health, win-win, cooperation or damage limitation strategies, for tackling health inequalities (see Ollila (2011) for a discussion of these strategies).

\section{The Policy Stream}

While there is broad agreement on the causes of health inequalities (Marmot, 2010; WHO, 2008), amongst health inequalities researchers there is less agreement on specific policy solutions based on available evidence (Smith and Kandlik Eltanani, 2015). While new evidence on the technical feasibility of ways to impact on health inequalities (McAuley et al., 2016; Richardson et al., 2020) can provide valuable insights, such evidence alone cannot answer questions about prioritisation. Policies can impact on (non-)health outcomes in different ways and over different timescales, have distinct cost implications, align with diverse ideological beliefs and may be based in sectors where health is not the primary outcome. Through the elicitation of public values insights can be gained on what policies the general public believe should be prioritised and what they would be willing to give-up for different distributions of (non-)health outcomes and the policies that can achieve them. This can inform our understanding of what the public would accept which may help such policies gain traction within policy communities and make it onto a short list of proposals that are developed in preparation of specific policy windows opening.

\section{The Politics Stream}

Knowledge of public values can help decision makers to understand the national mood on solutions to health inequalities. While exploration of lay perceptions of the causes of health inequalities is well established (Smith and Anderson, 2018), similar work on potential solutions 
is more limited (McHugh et al., 2019) and, crucially, evidence on public values for non-health policies in terms of their (non-)health outcomes does not exist. Grounding actions in the values of those affected by policy decisions could provide the mandate, acknowledged as missing and needed, for introducing more upstream policies to tackle health inequalities (Mackenbach, 2011; Whitehead and Popay, 2010). Likewise overcoming silos to act on social determinants of health (Carey and Crammond, 2015) can require an intersectoral approach to policy making which is also a well-known and politically-contentious issue, particularly as it can imply resource shifts across sectors. A receptive public could also help establish the political will necessary to facilitate cooperation across sectors for the implementation of upstream policies (WHO, 2014).

\section{Cross-Cutting Issues for Generating Evidence on Public Values}

While evidence of public values could help facilitate the opening of policy windows, Kingdon's (2011) MSA helps make explicit six potential cross-cutting issues when generating this new form of evidence. First, the public may value downstream, as opposed to upstream, policies which could result in the closure of policy windows for specific upstream policies. Given a prevailing view among the UK policy community is that the public lack appetite for more egalitarian policies (Smith, 2013) and there is evidence of individuals internalising neoliberal discourses (Peacock et al., 2014) such an outcome may occur. Second, due to the likelihood of plural views (McHugh et al., 2019) it is unlikely a clear mandate for specific policies will emerge. This then raises the question of what to do when people disagree? Third, the public may support less cost-effective policies which means, in the context of scarce resources, some health inequality reduction will be forgone. Fourth, at times, (desired) policy change for taking action on determinants of health can occur without public awareness of 
policy options (Embrett and Randall, 2014). Therefore, it is possible that the need for new evidence on public values to tackle health inequalities is overstated. Fifth, there is evidence that intersectoral approaches to policy making can result in non-health decision makers framing health as a means to achieve non-health sector objectives (Holt et al., 2016). Typically, this leads to a focus on more downstream policies, such as healthy eating, as opposed to more upstream, structural policies. Lastly, it is not clear whether evidence of public values on (non)health outcomes will hold weight with decision-makers in non-health sectors.

These are valid and important issues and highlight the need to explore the reasons for public values and how decision-makers would use such evidence. For this, undertaking qualitative work alongside, and/or independently of, work on public values is essential. Aggregative elicitation approaches are silent when it comes to rationales for public values. Qualitatively exploring why downstream, individualised policies and/or less cost-effective policies are favoured (if this is the case) would help to understand the reasons for such findings as well as why one upstream policy is preferred over another. Frameworks also exist for combining aggregative elicitation approaches with deliberative approaches, such as citizen's juries, to explore reasons, beliefs and principles underlying public values and provide ways to analyse and present plurality when people disagree (Baker et al., 2021). Understanding reasons for public values can aid the revision and adaption, or 'softening' (Kingdon, 2011), of policies to a form more likely to gain traction within policy communities. Exploring how (non-)health decision makers would use evidence of public values would also improve our understanding of how this evidence, in practice, affects policy processes and intersectoral policy making strategies. Additionally, it would help to identify the messages that work best for different audiences and the best communication strategies to achieve policy change. Finally, evidence of public values alone is unlikely to be sufficient, or always necessary, for policy change. 
However, such evidence has the potential to improve the chances of upstream policies making it onto the policy agenda to counteract the well-known lifestyle drift in policy making (Smith, 2013; Whitehead and Popay, 2010) as public support and acceptance is often considered necessary for radical policy change (Mackenbach, 2011).

\section{Conclusion}

COVID-19 has exposed and exacerbated existing health inequalities in the UK (Bambra et al., 2020; Marmot et al., 2020b). This has stimulated debate about whether policies in response to the pandemic should aim to "Build Back Better” or 'Build Back Fairer' (Marmot et al., 2020b, p4). In this context there is an opportunity for radical policy change and an even stronger case for implementing policies for tackling health inequalities. In a democracy, a necessary part of this debate ought to be ascertaining what type of society the public want to live in. A key part of this is understanding what policies the public believe should be introduced. For this, the public should be provided with the best available insights into the impact of different policies to inform their choices and enable the systematic and methodical elicitation of public values. This paper highlights how evidence of public values for non-health policies and their associated (non-)health outcomes could be elicited through the use of stated preference techniques and suggests this could facilitate the creation of policy windows for tackling health inequalities. Additionally, Kingdon’s MSA helps make explicit six cross-cutting issues when generating this new form of evidence. This suggests the need to explore reasons for public values and how decision-makers would use such evidence. With an awareness of these issues, evidence on public values has the potential to support upstream policies to tackle health inequalities. 


\section{Research Ethics Statement}

The author of this paper has declared that research ethics approval was not required since the paper does not present or draw directly on data/findings from empirical research.

\section{Funding}

This work was supported by a Wellcome Trust Discretionary Award (grant reference number 217292/Z/19/Z).

\section{Contributor Statement}

NM conceived the idea for the paper, wrote the first and subsequent drafts and made all edits/revisions to the paper.

\section{Conflicts of Interest}

The Author declares that there is no conflict of interest.

\section{Acknowledgements}

The Author wishes to thank Professors Rachel Baker and Cam Donaldson and Dr. Anna Macintyre for helpful comments on earlier drafts of the paper and for stimulating conversations that helped to develop the ideas contained in the paper. Thanks to the two anonymous reviewers for their constructive comments which helped to improve the paper. Versions of this paper also 
benefited from comments from participants at a symposium on 'Public Values, Plurality and Priority Setting' held at the GCU London campus in October 2019 and from participants at the Scottish Health Economics (SHE) launch conference in Dundee in October 2019. 


\section{References}

Bahamonde-Birke, F.J., Kunert, U., Link, H., 2015. The Value of a Statistical Life in a Road Safety Context — A Review of the Current Literature. Transport Reviews 35, 488511.

Baker, R., Mason, H., McHugh, N., Donaldson, C., 2021. Public values and plurality in health priority setting: what to do when people disagree and why we should care about reasons as well as choices. Social Science \& Medicine 277, 113892.

Bambra, C., Gibson, M., Sowden, A., Wright, K., Whitehead, M., Petticrew, M., 2010. Tackling the wider social determinants of health and health inequalities: evidence from systematic reviews. Journal of Epidemiology \& Community Health 64, 284291.

Bambra, C., Hayre, J., Pollock, A., Brown, H., 2020. COVID-19 and Health Inequality. The Independent SAGE Report 21, The Independent Scientific Advisory Group for Emergencies (SAGE).

Barnett, C., 2008. Convening Publics: The Parasitical Spaces of Public Action, in: The SAGE Handbook of Political Geography. SAGE Publications Ltd, United Kingdom, 403418.

Bateman, I.J., Carson, R.T., Day, B., Hanemann, W.M., Hanley, N., Hett, T., Jones Lee, M., Loomes, G., Mourato, S., Ozdemiroglu, E., Pearce, D.W., 2002. Economic Valuation With Stated Preference Techniques: A Manual. Edward Elgar.

Blackman, T., Harrington, B., Elliott, E., Greene, A., Hunter, D.J., Marks, L., McKee, L., Williams, G., 2012. Framing health inequalities for local intervention: comparative case studies: Framing health inequalities. Sociology of Health \& Illness 34, 49-63. 
Brunton, G., 2017. Narratives of community engagement: a systematic review-derived conceptual framework for public health interventions 15 .

Cairney, P., 2012. Understanding public policy: theories and issues. Red Globe Press.

Cairney, P., St Denny, E., 2020. Why Isn’t Government Policy More Preventive?, 1st ed. Oxford University Press.

Carey, G., Crammond, B., 2015. Action on the social determinants of health: Views from inside the policy process. Social Science \& Medicine 128, 134-141.

Carson, R.T., Hanemann, W.M., 2005. Chapter 17 Contingent Valuation, in: Maler, K.-G., Vincent, J.R. Handbook of Environmental Economics, Valuing Environmental Changes. Elsevier, 821-936.

Dahlgren, G., Whitehead, M., 2007. European strategies for tackling social inequities in health: Levelling up Part 2. World Health Organization. The Regional Office for Europe.

Dolan, P., Olsen, J.A., Menzel, P., Richardson, J., 2003. An inquiry into the different perspectives that can be used when eliciting preferences in health. Health Economics 12, 545-551.

Douglas, M., 2016. Beyond 'health': Why don’t we tackle the cause of health inequalities?, in: Health Inequalities: Critical Perspectives. Oxford University Press.

Embrett, M.G., Randall, G.E., 2014. Social determinants of health and health equity policy research: Exploring the use, misuse, and nonuse of policy analysis theory. Social Science \& Medicine 108, 147-155.

Escobar, O., 2017. Pluralism and Democratic Participation: What Kind of Citizen are Citizens Invited to be? Contemporary Pragmatism 14, 416-438.

Exworthy, M., 2008. Policy to tackle the social determinants of health: using conceptual models to understand the policy process. Health Policy and Planning 23, 318-327. 
Exworthy, M., Berney, L., Powell, M., 2002. “How great expectations in Westminster may be dashed locally": the local implementation of national policy on health inequalities. Policy \& Politics 30, 79-96.

Exworthy, M., Blane, D., Marmot, M., 2003. Tackling Health Inequalities in the United Kingdom: The Progress and Pitfalls of Policy: Tackling Health Inequalities in the United Kingdom. Health Services Research 38, 1905-1922.

Exworthy, M., Powell, M., 2004. Big Windows and Little Windows: Implementation in the “Congested State.” Public Administration 82, 263-281.

Fredriksson, M., Tritter, J.Q., 2017. Disentangling patient and public involvement in healthcare decisions: why the difference matters. Sociology of Health \& Illness 39, 95-111.

Hillier-Brown, F., Thomson, K., Mcgowan, V., Cairns, J., Eikemo, T.A., Gil-Gonzále, D., Bambra, C., 2019. The effects of social protection policies on health inequalities: Evidence from systematic reviews. Scand J Public Health 47, 655-665.

HM Treasury, 2020. The Green Book: Central Government Guidance on Appraisal and Evaluation.

Holt, D.H., Frohlich, K.L., Tjørnhøj-Thomsen, T., Clavier, C., 2016. Intersectoriality in Danish municipalities: corrupting the social determinants of health? Health Promot. Int.

Jones, M.D., Peterson, H.L., Pierce, J.J., Herweg, N., Bernal, A., Lamberta Raney, H., Zahariadis, N., 2016. A River Runs Through It: A Multiple Streams Meta-Review: A Multiple Streams Meta-Review. Policy Stud J 44, 13-36.

Kingdon, John.W., 2011. Agendas, alternatives, and public policies, updated 2nd Edition. ed. Longman. 
Kristiansen, I.S., Gyrd-Hansen, D., Nexøe, J., Bo Nielsen, J., 2006. Willingness-to-pay for a population program aimed at reducing dietary salt in Denmark. Preventive Medicine 43, 31-35.

Mackenbach, J.P., 2011. Can we reduce health inequalities? An analysis of the English strategy (1997—2010). Journal of Epidemiology and Community Health (1979-) 65, $568-575$.

Marmot, M., 2010. Fair Society: Healthy Lives. Strategic Review of Health Inequalities in England Post-2010, The Marmot Review.

Marmot, M., Allen, J., Boyce, T., Goldblatt, P., Morrison, J., 2020a. Health Equity in England: The Marmot Review 10 Years On. The Health Foundation.

Marmot, M., Allen, J., Goldblatt, P., Herd, E., Morrison, J., 2020b. Build Back Fairer: The COVID-19 Marmot Review. The Pandemic, Socioeconomic and Health Inequalities in England. Institute of Health Equity, London.

McAuley, A., Denny, C., Taulbut, M., Mitchell, R., Fischbacher, C., Graham, B., Grant, I., O’Hagan, P., McAllister, D., McCartney, G., 2016. Informing Investment to Reduce Inequalities: A Modelling Approach. PLoS ONE 11, e0159256.

McHugh, N., Baker, R., Biosca, O., Ibrahim, F., Donaldson, C., 2019. Who knows best? A Q methodology study to explore perspectives of professional stakeholders and community participants on health in low-income communities. BMC Health Serv Res 19, 35.

McNamara, S., Holmes, J., Stevely, A.K., Tsuchiya, A., 2020. How averse are the UK general public to inequalities in health between socioeconomic groups? A systematic review. Eur J Health Econ 21, 275-285. 
Ogilvie, D., 2005. Systematic reviews of health effects of social interventions: 2. Best available evidence: how low should you go? Journal of Epidemiology \& Community Health 59, 886-892.

Ollila, E., 2011. Health in All Policies: From rhetoric to action. Scand J Public Health 39, 1118.

Peacock, M., Bissell, P., Owen, J., 2014. Dependency denied: Health inequalities in the neoliberal era. Social Science \& Medicine 118, 173-180.

Petticrew, M., 2004. Evidence for public health policy on inequalities: 1: The reality according to policymakers. Journal of Epidemiology \& Community Health 58, 811816.

Popay, J., 2006. Community engagement for health improvement: questions of definition, outcomes and evaluation. A background paper prepared for NICE. NICE, London.

Reid, S., Montagu, I., Scholes, A., 2019. Scottish Social Attitudes 2019: Attitudes to government and political engagement, An Official Statistics publication for Scotland. ScotCen Social Research. Scottish Government.

Richardson, E., Fenton, L., Parkinson, J., Pulford, A., Taulbut, M., McCartney, G., Robinson, M., 2020. The effect of income-based policies on mortality inequalities in Scotland: a modelling study. The Lancet Public Health 5, e150-e156.

Ryan, M., Scott, D.A., Reeves, C., Bate, A., van Teijlingen, E.R., Russell, E.M., Napper, M., Robb, C.M., 2001. Eliciting public preferences for healthcare: a systematic review of techniques. Health Technol Assess 5.

Scottish Government, 2020. Long-term Monitoring of Health Inequalities: January 2020 report, An Official Statistics publication for Scotland. Health and Social Care.

Shackley, P., Dixon, S., 2000. Using contingent valuation to elicit public preferences for water fluoridation 777-787. 
Smith, K.E., 2013. Beyond Evidence-Based Policy in Public Health: The Interplay of Ideas. Palgrave Macmillan UK.

Smith, K.E., 2007. Health inequalities in Scotland and England: the contrasting journeys of ideas from research into policy. Social Science \& Medicine 64, 1438-1449.

Smith, K.E., Anderson, R., 2018. Understanding lay perspectives on socioeconomic health inequalities in Britain: a meta-ethnography. Sociology of Health \& Illness 40, 146170.

Smith, K.E., Bambra, C., Hill, S.E., 2015. Health Inequalities: Critical Perspectives, Health Inequalities. Oxford University Press.

Smith, K.E., Kandlik Eltanani, M., 2015. What kinds of policies to reduce health inequalities in the UK do researchers support? Journal of Public Health 37, 6-17.

Smith, K.E., Katikireddi, S.V., 2013. A glossary of theories for understanding policymaking. J Epidemiol Community Health 67, 198-202.

Solar, O., Valentine, N., Rice, M., Albrecht, 2009. Moving Forward to Equity In Health: What kind of intersectoral action is needed? An approach to an intersectoral typology. Presented at the 7th Global Conference For Health Promotion, Nairobi, Kenya.

Stewart, E., 2016. Publics and Their Health Systems. Palgrave Macmillan UK, London.

Tenbensel, T., 2010. Virtual special issue introduction: Public participation in health policy in high income countries - A review of why, who, what, which, and where? Social Science \& Medicine 71, 1537-1540.

Thomson, K., Hillier-Brown, F., Todd, A., McNamara, C., Huijts, T., Bambra, C., 2018. The effects of public health policies on health inequalities in high-income countries: an umbrella review. BMC Public Health 18, 869.

Tsuchiya, A., Watson, V., 2017. Re-Thinking 'The Different Perspectives That can be Used When Eliciting Preferences in Health.' Health Econ. 26. 
Whitehead, M., Popay, J., 2010. Swimming upstream? Taking action on the social determinants of health inequalities. Social Science \& Medicine 71, 1234-1236.

WHO, 2014. Health in all policies: Helsinki statement, framework for country action : the 8th Global Conference on Health Promotion jointly organized by. World Health Organization.

WHO, 2012. Intersectoral governance for health in all policies - structures, actions and experiences. World Health Organization on behalf of the European Observatory on Health Systems and Policies.

WHO, 2008. Closing the gap in a generation: health equity through action on the social determinants of health. Final report of the Commission on Social Determinants of Health. World Health Organisation. Commission on Social Determinants of Health. Zahariadis, N., 2007. The Multiple Streams Framework, in: Theories of the Policy Process. Westview, Cambridge, MA. 